\title{
ANALISIS ALGORITMA BACKPROPAGATION DALAM MEMPREDIKSI TINGKAT KEBERHASILAN PELATIH SEPAKBOLA SEBAGAI SALAH SATU KEMAJUAN OLAHRAGA DI INDONESIA
}

\author{
Muhammad Ridwan Lubis 1, Iin Parlina 2 \\ 1,2 AMIK Tunas Bangsa Pematangsiantar \\ Jalan Jendral Sudirman Blok A Nomor 1, 2, 3 Pematangsiantar \\ ridwanlubis@amiktunasbangsa.ac.id 1, iinparlina@amiktunasbangsa.ac.id ${ }^{2}$
}

\begin{abstract}
The development of sports is an important role of a trainer and the management role that is in it. Determining the success of the trainer by using the criteria of experience, strategy and understanding of the trainer on the mental and spiritual conditions of each player is the first step in achieving success. Research using computational-based information technology is very much developed mainly by using neural network methods. Research using Artificial Neural Networks has been widely used, especially in the field of sports, especially football, including prediction results of soccer matches. In this study, the study of determining the success rate of soccer coaches as one of the advances in Indonesian football sports using the backpropagation algorithm was the goal of researchers to produce an effective decision in determining the success of football sports in Indonesia.
\end{abstract}

Keywords: Coach, Football, Artificial Neural Network, Backpropagation Indonesian

\section{Abstrak}

Perkembangan olahraga merupakan peran penting dari seorang pelatih dan peran manajemen yang ada didalamnya. Menentukan tingkat keberhasilan pelatih dengan menggunakan kriteria pengalaman, strategi dan pemahaman pelatih terhadap kondisi mental dan spiritual setiap pemain merupakan langkah awal dalam mencapai keberhasilan. Penelitian dengan menggunakan teknologi informasi berbasis komputasi sangat banyak dikembangkan terutama dengan menggunakan metode neural network. Penelitian dengan menggunakan Jaringan Saraf Tiruan sudah banyak digunakan terutama dalam bidang olahraga terutama sepakbola, diantaranya adalah Prediksi hasil pertandingan sepak bola. Pada penelitian ini, penelitian tetang menentukan tingkat keberhasilan pelatih sepakbola sebagai salah satu kemajuan olahraga sepakbola diindonesia menggunakan algoritma backpropagation menjadi tujuan peneliti untuk menghasilkan sebuah keputusan yang efektif dalam menentukan keberhasilan olahraga sepakbola di indonesia.

Kata kunci: Pelatih, Sepakbola, Jaringan Saraf Tiruan, Backpropagation, Indonesia 


\section{PENDAHULUAN}

\subsection{Latar Belakang Penelitian}

Perkembangan olahraga merupakan peran penting dari seorang pelatih dan peran manajemen yang ada didalamnya. Manajemen dalam memilih pelatih merupakan salah satu cara untuk meningkatkan keberhasilan sebuah tim olahraga agar dapat memberikan prestasi terbaik untuk untuk bangsa dan negaranya. Di indonesia, salah satu olahraga yang perlu mendapat perhatian adalah Sepak bola. Agar olahraga sepak bola di negara kita berkembang diperlukan pelatih yang bukan hanya pandai dalam mengolah bola dengan kaki, tetapi perlu dalam memahami kondisi psikologis pemain.

Berdasarkan sejarah kepelatihan sepak bola di indonesia dimulai dari tahun 1938, hindia belanda (indonesia) banyak prestasi yang diraih pada saat itu. Dilatih oleh seorang berkebangsaan belanda, indonesia berhasil mengukir prestasi sebagai peserta piala dunia di tahun 1938. Tahun 1951 berhasil melaju ke babak perempat final piala ASIA (Asian Games). Tahun 1956, di era kepelatihan Antun “ Thony" Pogacnik (Yugoslavia) berhasil mengantarkan indonesia peringkat empat piala Asia (1954), meraih medali perunggu tahun 1958 dan masuk kualifikasi piala dunia pada tahun 1978.

Setelah era kepelatihan warga negara asing, beberapa pelatih asal negara sendiri juga banyak mengukir prestasi yang membanggakan diantaraya Endang Witarsa (1960 - 1970) berhasil ke perempat final Asian Games tahun 1966), Juara Piala Raja tahun 1968 dan runner up piala raja tahun 1969. Seiring perkembangan waktu pada era tahun 2000 hingga saat ini kondisi indonesia di olahraga sepak bola mengalami penurunan yang perlu mendapat perhatian.

Untuk meningkatkan keberhasilan olahraga sepak bola di indonesia di tingkat internasional, manajemen memegang peranan penting dalam menentukan siapa pelatih yang berkualitas dalam memahami kondisi dan psikologi pemain. Diperlukan sejumlah data pendukung pelatih seperti biografi pelatih selama menjadi seorang juru taktik sebuah klub sepakbola [1]. Berikut data prestasi beberapa pelatih sepak bola di indonesia di tingkat nasional dan internasional dari tahun 2010 - sekarang.

Tabel 1. Pelatih Tim Nasional Indonesia Tahun 2010- sekarang

\begin{tabular}{lllll}
\hline NO & Nama Pelatih & $\begin{array}{c}\text { Warga Negara } \\
\text { Asal }\end{array}$ & $\begin{array}{c}\text { Era } \\
\text { Kepelatihan }\end{array}$ & \multicolumn{1}{c}{$\begin{array}{c}\text { Prestasi yang } \\
\text { diraih }\end{array}$} \\
\hline 1 & Alfred Riedl & Austria & $2010-2011$, & - \\
& & 2013 dan & 2010 \\
& & $2014-2016$ & - Fase Grup Piala AFF \\
& & & 2012 \\
& & & - Runner-up Piala AFF \\
& & & & 2016 \\
2 & Wim Rijsbergen & Belanda & $2011-2012$ & Kualifikasi piala dunia \\
& & & & 2014
\end{tabular}

3 Aji Santoso Indonesia $\quad 2012 \quad$ Kualifikasi piala dunia 


\begin{tabular}{|c|c|c|c|c|}
\hline NO & Nama Pelatih & $\begin{array}{c}\text { Warga Negara } \\
\text { Asal }\end{array}$ & $\begin{array}{c}\text { Era } \\
\text { Kepelatihan }\end{array}$ & $\begin{array}{c}\text { Prestasi yang } \\
\text { diraih }\end{array}$ \\
\hline & & & & 2014 \\
\hline 4 & Nilmaizar & Indonesia & $2012-2013$ & $\begin{array}{l}\text { - Piala AFF } 2012 \\
\text { Kualifikasi Piala Asia } \\
2015 \\
\text { - Piala Internasional } \\
\text { Palestina } 2012\end{array}$ \\
\hline 5 & Rahmad Darmawan & Indonesia & 2013 & $\begin{array}{l}\text { Kualifikasi Piala Asia } \\
2015\end{array}$ \\
\hline 6 & Jacksen F Tiago & Brazil & 2013 & $\begin{array}{l}\text { Kualifikasi Piala Asia } \\
2015\end{array}$ \\
\hline 7 & Luis Milla & Spanyol & 2016-Sekarang & $\begin{array}{l}\text { Medali Perunggu SEA } \\
\text { Games } 2016 \\
\text { Fase Grup Piala Asia } \\
2018\end{array}$ \\
\hline
\end{tabular}

Dari tabel 1.1 diatas menjelaskan tentang prestasi tim nasional indonesia dari tahun 2010 pada era pelatih asal austria hanya meraih posisi runner up piala AFF tahun 2010 dan 2016 sedangkan tahun 2012 hanya berhasil pada fase grup piala AFF. Tahun 2012 indonesia yang dilatih oleh pelatih asal negara sendiri belum bisa lolos ke fase grup piala dunia 2014 dan piala Asia 2013. Tahun 2016 sekarang indonesia dilatih oleh pelatih asal negara spanyol dan prestasi perdana meraih medali perunggu SEA Games 2016.

Dari penjelasan diatas, dapat kita lihat grafik prestasi pelatih dari tahun 2010sekarang.

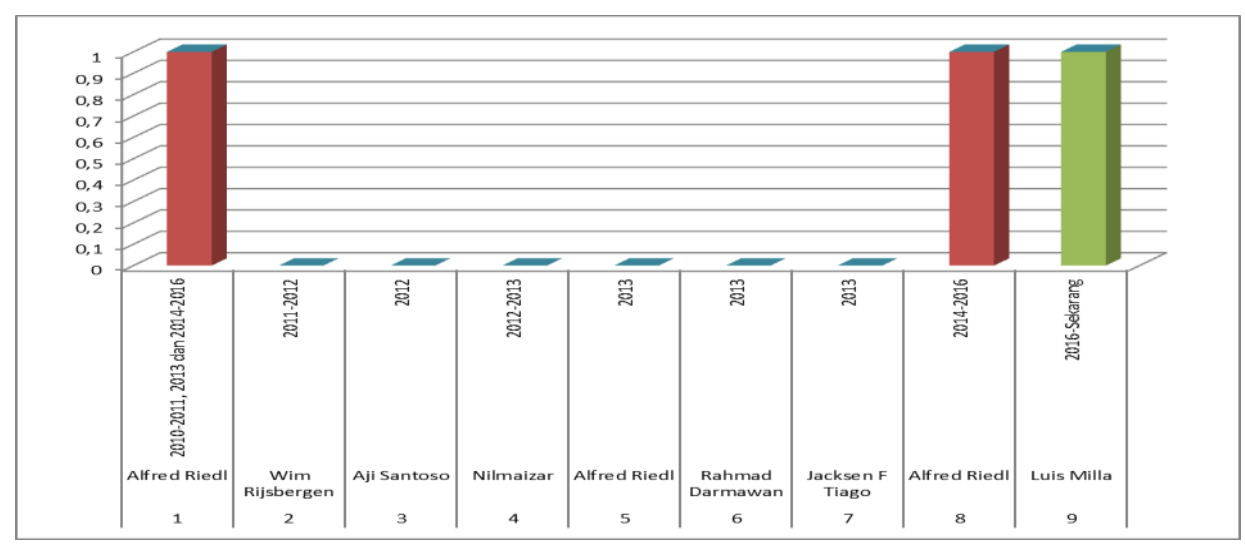

Gambar 1. Grafik Prestasi Pelatih Tim Indonesia 
Gambar 1. menjelaskan prestasi indonesia dari tahun 2010 sampai sekarang meraih prestasi sebagai runner up 2 kali (merah) dan medali perunggu 1 kali (hijau).

Melihat kondisi indonesia, peningkatan prestasi olahraga sepak bola indonesia dapat lebih ditingkatkan dengan dukungan rakyat indonesia dengan jumlah 200 juta penduduk sangat mendukung pekermbangan olahraga sepak bola agar dapat mengikut ajang internasional dan bisa mengikuti kompetisi seperti piala dunia yang menjadi target pelatih tim nasional indonesia saat ini dan dapat memajukan olahraga sepak bola di indonesia.

\subsection{Rumusan Masalah}

Berdasarkan latar belakang yang telah diuraikan diatas maka rumusan masalah pada penelitian ini adalah bagaimana memajukan olahraga sepak bola di indonesia.

\subsection{Tujuan Penelitian}

Adapun tujuan penelitian ini adalah menggunakan algoritma jaringan saraf tiruan untuk menganalisis tingkat keberhasilan pelatih sepak bola sebagai salah satu upaya memajukan olahraga di indonesia.

\section{METODOLOGI PENELITIAN}

\subsection{Definisi Neural Network}

Jaringan saraf tiruan (neural network) merupakan salah satu aplikasi buatan manusia yang selalu mencoba untuk mensimulasikan proses pembelajaran pada otak manusia tersebut[2]. Jaringan saraf tiruan dapat belajar dari pengalaman, melakukan generalisasi atas contoh yang diperolehnya dan mengabstraksi karakteristik esensial masukan bahkan untuk data yang tidak relevan [3].

\subsection{Definisi Pelatih}

Seorang pelatih memegang peranan yang vital dalam pengembangan kemampuan para atlet. Pelatih adalah bagian yang signifikan dalam proses latihan, sebagaimana guru didalam proses pendidikan [4].

\subsection{Algoritma Backptopagation}

Sesuai dengan ketentuan yang ada pada Bab Pendahuluan, penulis sudah menjelaskan tujuan menggunakan metode Jaringan Saraf Tiruan adalah untuk Menentukan Tingkat Keberhasilan Pelatih Sepakbola dengan Algoritma Backpropagation. Tujuan menggunakan Metode ini adalah untuk menghasilkan nilai terbaik dengan menggunakan metode neural network model Backpropagation. Diharapkan dapat memberikan manfaat khususnya bagi penulis dan berguna bagi perkembangan penelitian selanjutnya [5]. 


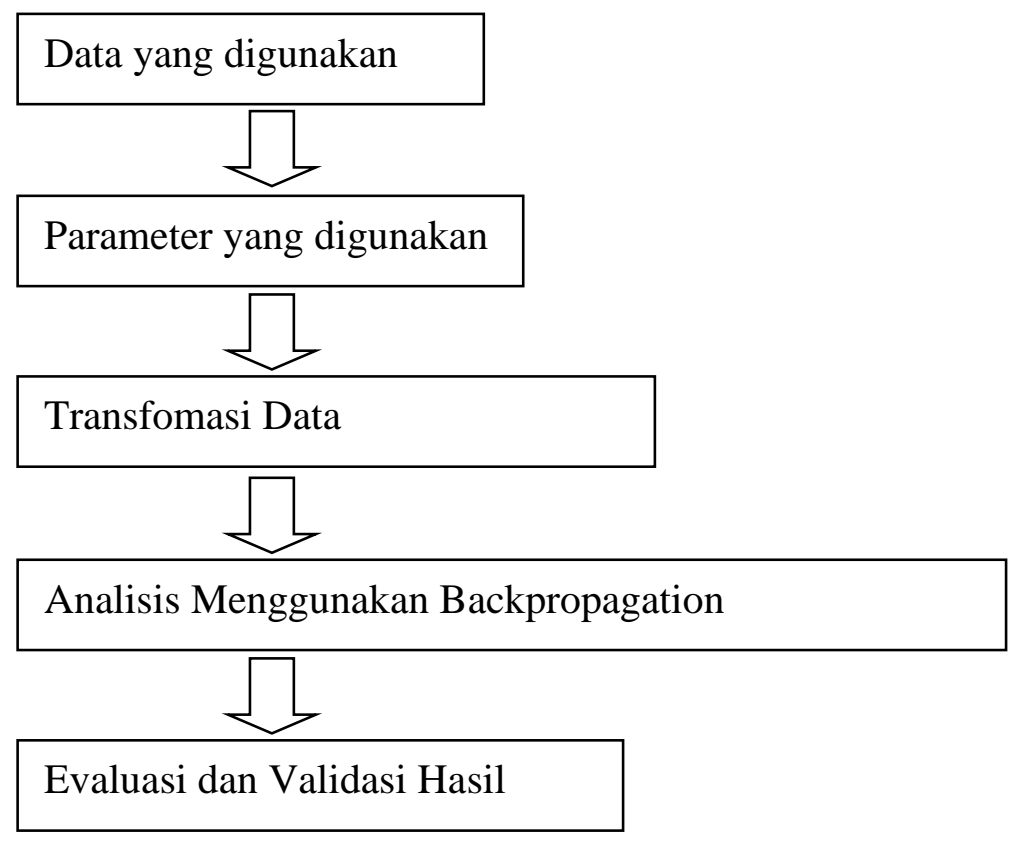

Gambar 2. Tahapan Penelitian

Pada rancangan proses, ada beberapa tahapan yang penulis konsep untuk mendapatkan hasil prediksi. Berikut ini penjelasan dari beberapa tahapan pada rancangan proses :

a. Data yang digunakan

Data yang digunakan pada peneltian ini adalah data pelatih sepakbola indonesia dari tahun 2010-2018.

b. Parameter yang digunakan

Parameter yang digunakan dalam penelitian ini adalah : fisik, mental, psikologis, kemampuan membaca situasi, prestasi

c. Transformasi Data

Pada tahap tranformasi data dilakukan proses komputasi data dengan menggunakan Persamaan 3.1

$\mathrm{X}^{1}=\frac{(X-X \min )(b-\alpha)}{(X \max -X \min )}+\alpha$

Keterangan :

$\mathrm{X}^{1}$ adalah Nilai Transformasi ,X adalah nilai asli

Xmin adalah nilai minimal pada satu kolom data, XMax adalah nilai maksimal pada satu kolom data, b, $\alpha$ adalah nilai atas dan nilai bawah (antara $0,1 . .0,9$ ).

Proses transformasi dilakukan dengan ketentuan menggunakan parameter yang sudah ditentukan [3]. 
d. Analisis Menggunakan Metode Backpropagation

Seperti yang sudah dijelaskan pada Bab 1 mengenai Metode yang digunakan untuk analisis jaringan saraf tiruan, penulis menerapkan metode Neural Network backpropagation untuk mendefinisikan nilai awal seperti nilai input data (weight), bias dan nilai output (y) yang diharapkan [6]. Tahap awal pembelajaran ditandai dengan menentukan arsitektur neural network yang terdiri dari 8 (delapan) input, 1 (satu) hidden layer dengan jumlah $n$ neuron dan 2 (dua) output [7].

Untuk memprediksi hasil dengan metode backpropagation, algoritma yang digunakan adalah sebagai berikut :

1) Menentukan jenis arsitektur Back Propagation dan menentukan jumlah neuron pada hidden layer. Untuk menentukan jumlah neuron pada hidden layer berada diantara jumlah neuron pada input layer dan output layer.

2) Inisialiasi bobot dan bias awal secara random dengan nilai antara -1 sampai dengan 1

3) Menyebarkan data pada input layer menuju hidden layer dengan mengalikan setiap data pada unit neuron input layer dengan bobot yang menghubungkan antar neuron, hasil perkalian tersebut dijumlahkan lalu ditambahkan dengan biasnya.

4) Masing-masing sinyal diaktifkan dengan fungsi aktifasi sigmoid.

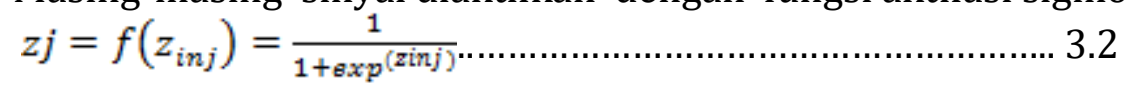

5) Sinyal yang telah diaktifkan dikirim menuju output layer dengan cara mengalikan sinyal pada hidden layer dengan bobot yang menghubungkan antar neuron ke output layer. Hasil perkalian tersebut dijumlahkan lalu ditambahkan dengan biasnya.

$y_{-} i n_{k=w o_{k}}+\sum_{j=1}^{p} z j+w j k$.

$\mathrm{Y} 1=\mathrm{k} 1 . \mathrm{w} 1+\mathrm{k} 2 . \mathrm{w} 2$

$=0.28458 * 0.2+0.5393 * 0.4=0.12137$

$\mathrm{Y} 2=\mathrm{k} 1 . \mathrm{w} 1+\mathrm{k} 2 . \mathrm{w} 2$

$=0.28458 *-0.3+0.5393 * 0.1=-0.29231$

6) Neuron pada ouput layer diaktifkan agar mendapatkan hasil keluaran pada tahap ini.

$y k=f\left(y_{\text {ink }}\right)$

Selanjutnya, jika hasil yang didapat pada forward propagation belum mendekati target maka proses backpropagation dilakukan dengan menentukan nilai error pada masing-masing unit yang ada pada hidden layer dan output layer. Kemudian nilai error pada hidden dan output akan menjadi nilai input yang digunakan untuk mengupdate weight untuk nilai input yang baru. Proses ini akan terus dilakukan (iterasi) sampai ke $n$ dan akan berhenti jika target yang ditetapkan sudah optimal. pada tahapan Propagasi Balik [5]. 
e. Evaluasi dan Hasil

Untuk evaluasi dan hasil yang diperoleh dengan menggunakan algoritma neural network backpropagation dengan menerapkan beberapa model arsitektur dengan menggunakan Aplikasi Matlab versi 6.1 akan dijelaskan pada Hasil dan Pembahasan.

\section{HASIL DAN PEMBAHASAN}

Berdasarkan data pelatihan dan pengujian yang dilakukan dengan menggunakan Algoritma jaringan saraf tiruan backpropagation yang menggunakan beberapa model arsitektur Backpropagation, diperoleh beberapa keluaran dengan analisis sebagai berikut :

Hasil pelatihan dan pengujian dengan Arsitektur 8-2-1

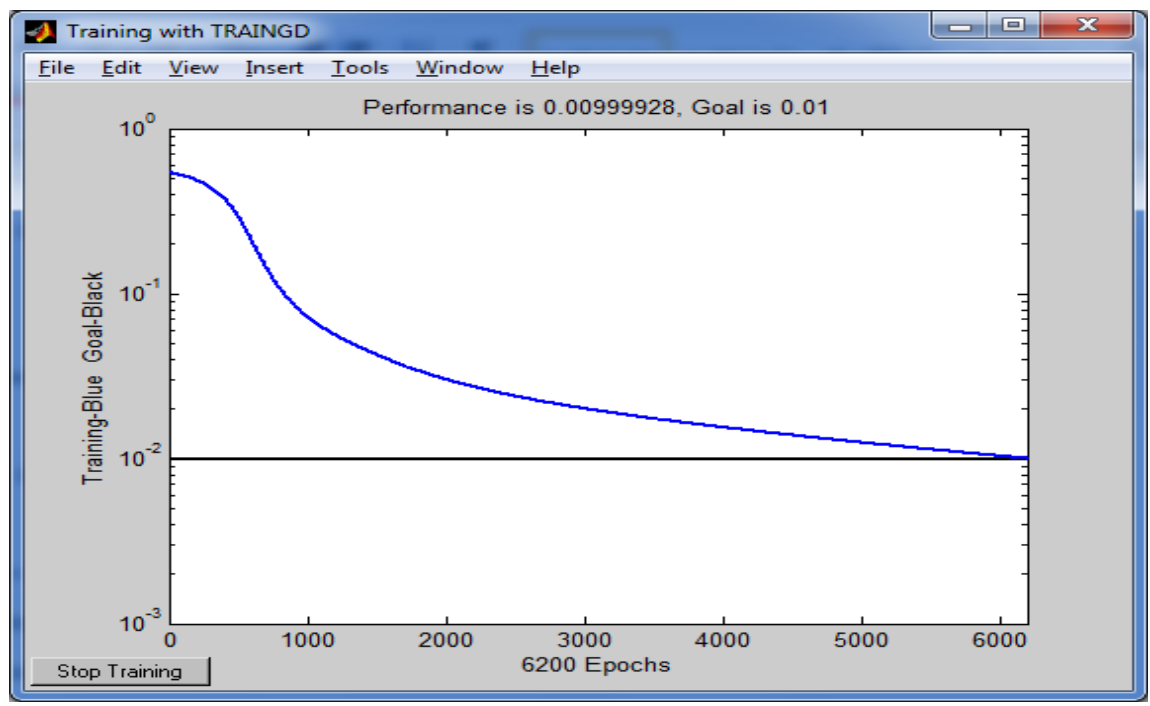

Gambar 3. Grafik Arsitektur 8-2-1

Berdasarkan hasil pada grafik diatas dengan model arsitektur 8-2-1 jumlah iterasi yang dihasilkan sebanyak 6200 epoch menghasilkan akurasi sebesar 0.0099928 dengan learning rate 0.01 
Hasil pelatihan dan pengujian dengan Arsitektur 8-3-1

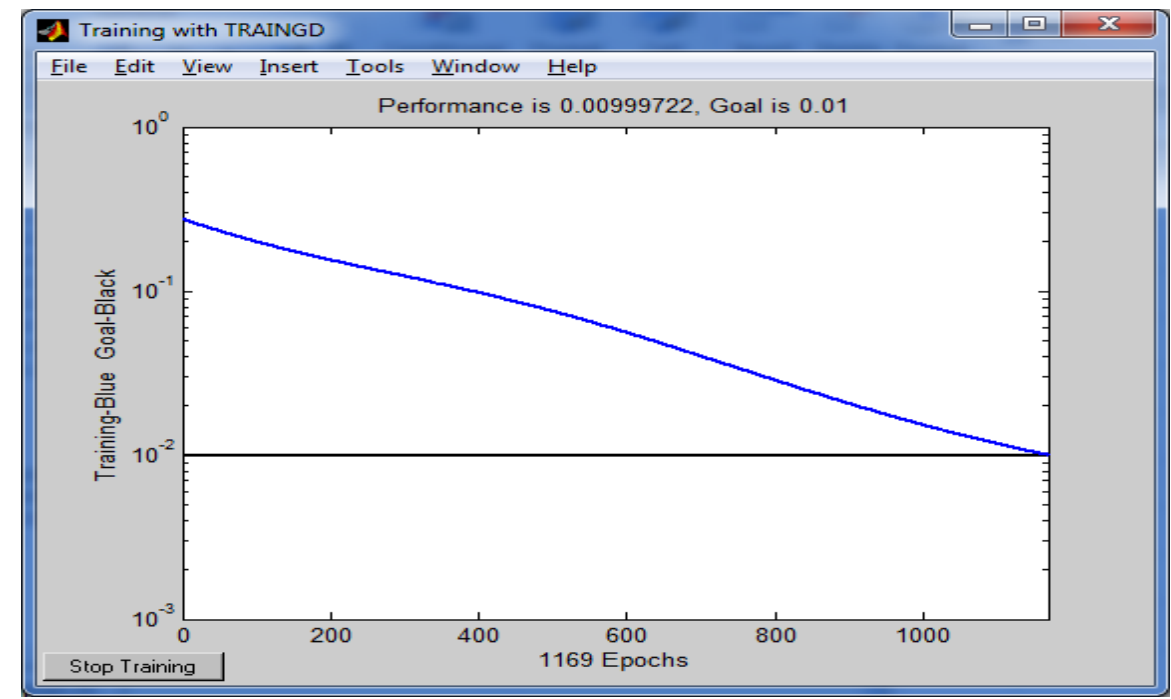

Gambar 4. Grafik Arsitektur 8-3-1

Berdasarkan hasil pada grafik diatas pengujian dengan model arsitektur 8-3-1 dengan jumlah iterasi sebanyak 1169 epochs menghasilkan akurasi sebesar 0.00999722 dengan learning rate 0.01

Hasil pelatihan dan pengujian dengan Arsitektur 8-4-1

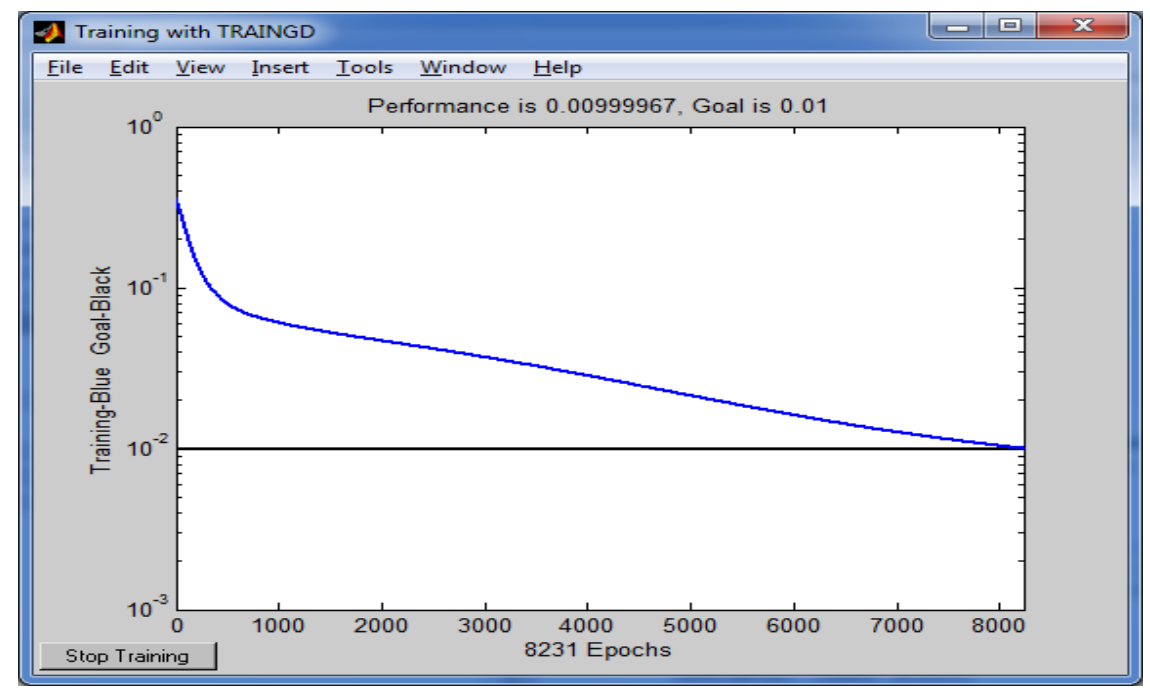

Gambar 5. Grafik Model Arsitektur 8-4-1 
Berdasarkan hasil pada grafik diatas pengujian dengan model arsitektur 8-4-1 dengan jumlah iterasi sebanyak 8231 epochs menghasilkan akurasi sebesar 0.00999967 dengan learning rate 0.01

Hasil pelatihan dan pengujian dengan Arsitektur 8-5-1

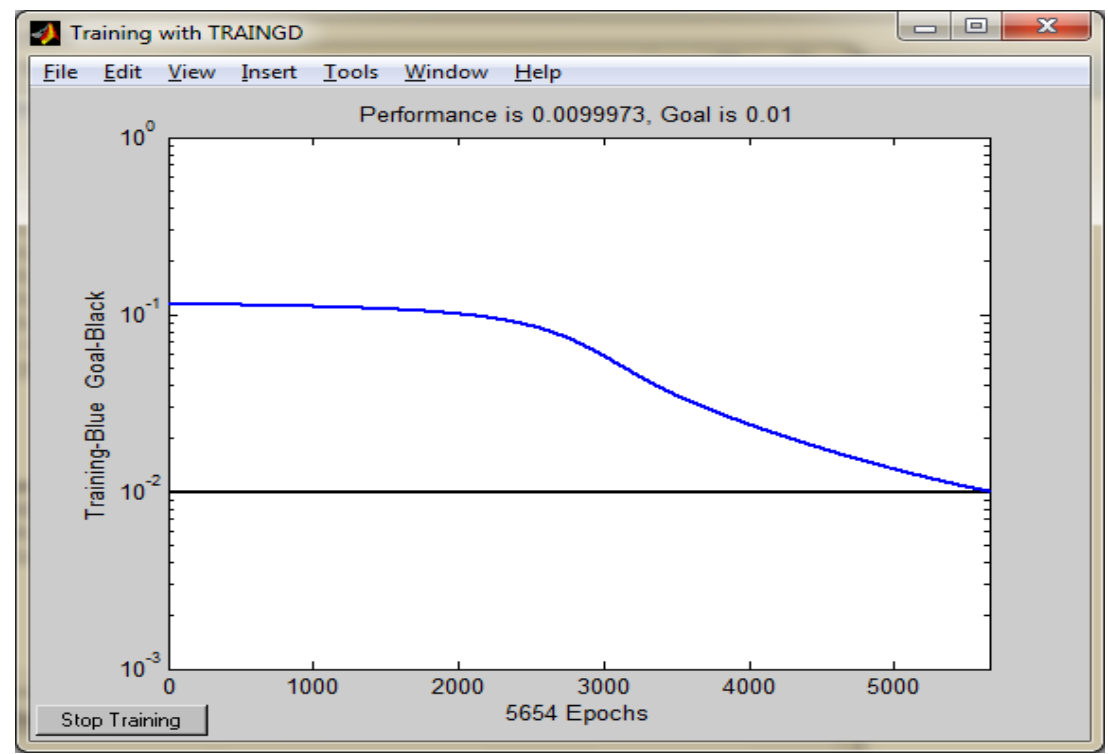

Gambar 6. Grafik Model Arsitektur 8-4-1

Berdasarkan hasil pada grafik diatas pengujian dengan model arsitektur 8-3-1 dengan jumlah iterasi sebanyak 5654 epochs menghasilkan akurasi sebesar 0.0099973 dengan learning rate 0.01

Hasil pelatihan dan pengujian dengan Arsitektur 8-6-3-1

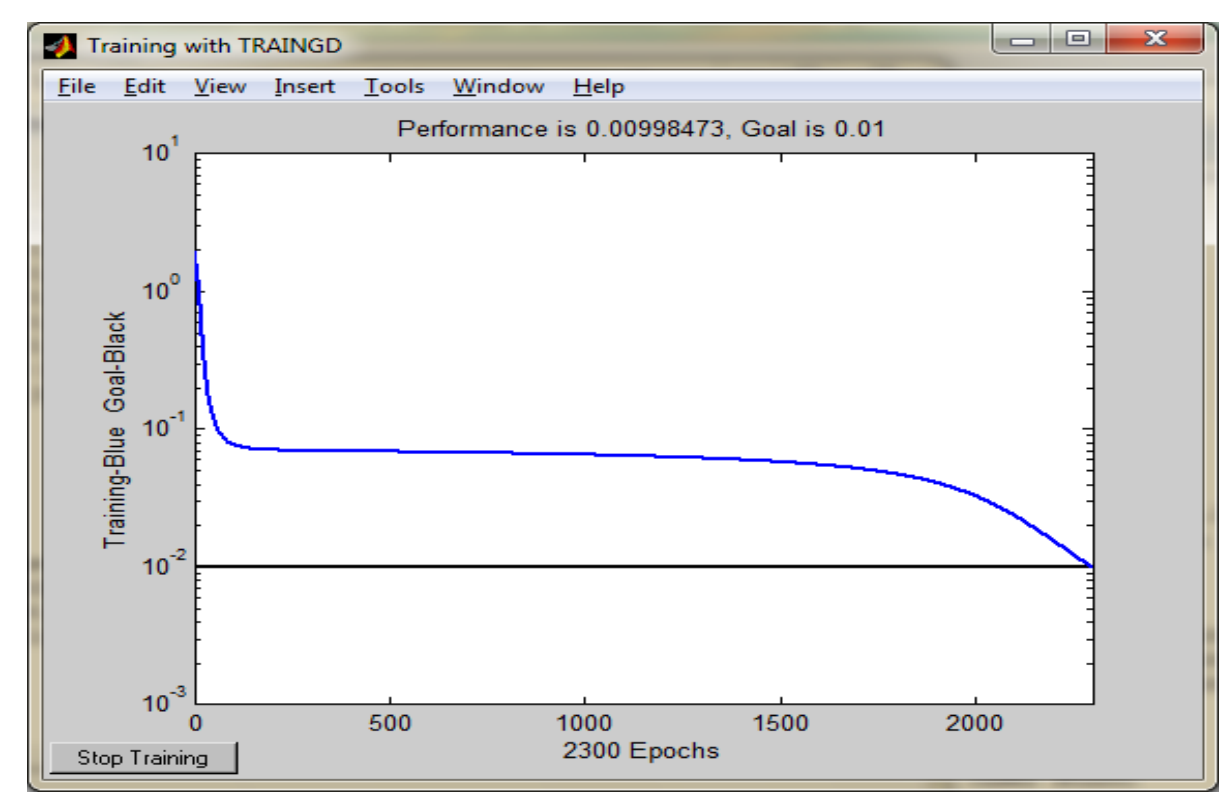

Gambar 7. Grafik Model Arsitektur 8-4-1 
Berdasarkan hasil pada grafik diatas pengujian dengan model arsitektur 8-6-3-1 dengan jumlah iterasi sebanyak 2300 epochs menghasilkan akurasi sebesar 0.00998473 dengan learning rate 0.01

\section{SIMPULAN}

Berdasarkan data pelatihan dan pengujian yang dilakukan tentang analisis neural network backpropagation untuk menentukan tingkat kebarhasian pelatih sepeakbola dapat disimpulkan beberapa kesimpulan sebagai berikut :

a. Model Arsitektur yang memiliki hidden lebih banyak tidak menjadi langkah terbaik dalam menghasilkan output terbaik dengan nilai error minimal

b. Arsitektur terbaik pada data pengujian dan pelatihan adalah model 8-3-1 dengan jumlah iterasi sebanyak 1169.

c. Hasil dari Penelitian diatas merupakan penerapan model arsitektur sederhana yang digunakan untuk menentukan tingkat keberhasilan pelatih sepakbola dengan algoritma backpropagation yang perlu dkembangkan lebih kompleks pada penelitian selanjutnya dengan menggunakan data pengujian lebih banyak sehingga memperoleh hasil terbaik.

\section{UCAPAN TERIMA KASIH}

Ucapan terima kasih kami sampaikan kepada Direktorat Riset dan Pengabdian Masyarakat Direktorat Jenderal Penguatan Riset dan Pengembangan Kementerian Riset, Teknologi dan Pendidikan Tinggi atas Pendanaan Penelitian Dosen Pemula (PDP) tahun pelaksanaan 2019.

\section{DAFTAR PUSTAKA}

[1] E. R. SUKAMTI, "Profesional pelatih cabang olahraga yang berkarakter untuk mencapai prestasi maksimal."

[2] M. R. Lubis, "Analisis jaringan saraf tiruan back propgation untuk peningkatan akurasi prediksi hasil pertandingan sepakbola," Jurnal Teknik Informatika, vol. 10, no. 1, pp. 51-62, 2018.

[3] A. P. Windarto, M. R. Lubis, and S. Solikhun, "Implementasi JST pada Prediksi Total Laba Rugi Komprehensif Bank Umum dan Konvensional dengan Backpropagation," Jurnal Teknologi Informasi dan Ilmu Komputer, vol. 5, no. 4, p. 411, 2018.

[4] Y. Kurniwan and M. S. Dr. Ayub Ilfandy Imran, B.Sc., "No Title," e-Prociding of Management, vol. 5, no. 1, pp. 1382-1390, 2018.

[5] M. R. Lubis, "Model Jaringan Saraf Tiruan Backpropagation Untuk Meningkatkan Penguasaan Mahasiswa Pada Matakuliah Algoritma Dan Pemrograman," Jurnal Informatika dan Komputer, vol. XXI, no. 1, pp. 91-94, 2019.

[6] C. Science, "English Premier League ( EPL ) Soccer Matches Prediction using 
An Adaptive Neuro - Fuzzy Inference System ( ANFIS ) for," no. 2003, pp. 39, 2015.

[7] S. M. Arabzad, M. E. T. Araghi, and S. Soheil, "Applied Research on Industrial Engineering Football Match Results Prediction Using Artificial Neural Networks; The," International Journal of Applied Research on Industrial Engineeering, vol. 1, no. October, pp. 159-179, 2014. 